\title{
A Study on the Effect of Soil and Sediment Types on the Fugacity Based Multimedia Partitioning of a Contact Fungicide Fluopyram: An Equilibrium Quality Criterion (EQC) Level 1 Approach
}

\author{
A. Thakur*, S. Sharma** and K. Qanungo*† \\ *Division of Chemistry, University Institute of Science, Chandigarh University, Gharuan, Distt. Mohali-140413, Punjab, \\ India \\ **N-307, Gilco Heights, Gilco Valley, Kharar, Mohali, Punjab, 140301, India \\ $†$ Corresponding author: K. Qanungo; kushal.appsci@ cumail.in
}

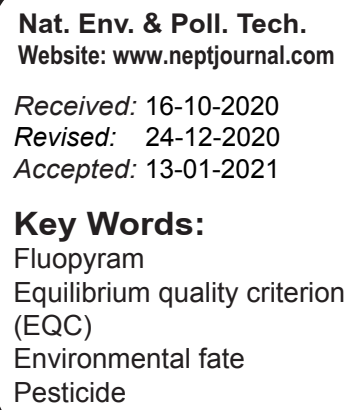

\section{ABSTRACT}

Equilibrium Quality Criterion (EQC) Level I calculations have been performed with Standard Equilibrium Quality Criterion (EQC) environment to study the environmental partitioning of a fungicide Fluopyram. Equilibrium Quality Criterion (EQC) Level I calculation assumes no degradation of the chemical, steady-state, and equilibrium conditions between the environmental compartments. The results reveal that the concentration of Fluopyram is expected to be maximum in the sediment compartment, followed by soil and water compartments. The effect of soil and sediment types on partitioning has been studied by systematically varying the densities of these two compartments. In the sediment compartment, the Fluopyram concentration is predicted to be highest if the sediment type is 'sandy' and the soil type is 'clay'.

\section{INTRODUCTION}

The use of chemical pesticides in farming is one of the principal facets of modern agricultural practices. These pesticides come in a wide variety of types like contact and non-contact pesticides, selective, non-selective, etc., and functions like herbicides, fungicides, bactericides, nematicides, etc. (Duran-Lara et al. 2020). All of these pesticides are toxic not only to humans but also to flora and fauna (Bernardes et al. 2015). After their intended use of these pesticides in agricultural fields, these pesticides are left in the environment to degrade and dissipate. Many of these pesticides end up polluting the sea and surface water, sediments, and air. Their concentrations in these environmental compartments can be determined experimentally using a standard analytical procedure or estimated by the use of environmental fate models ( $\mathrm{Di}$ Guardo et al. 2018).

Fluopyram is a new pyridylethylamide insecticide with a wide-ranging fungicidal and nematocidal action and has extensive potential use in agriculture worldwide (Persistence Market Research 2020). It is identified to be toxic to aquatic organisms (Malhotra 2018, EFSA 2013) and hence it is not used near places where aquaculture is practiced.
Considering the importance of Fluopyram in agriculture and the need to the study environmental fate of pesticides, this paper describes the effect of soil and sediment type on the environmental fate of Fluopyram using a fugacity-based Equilibrium Quality Criterion Model “EQC Model' (Mackay 2004). The EQC model has been used in several studies to predict the environmental fate of chemicals in the environment (Macleod \& Mackay 1999, Cahill et al. 2003, Ellis et al. 2006, Lifongo \& Nfon 2009, Ndouba et al. 2020, Kim et al. 2013).

\section{MATERIALS AND METHODS}

The Level I of the Equilibrium Criterion (EQC) model has been used in this study (Mackay 2001). There are several assumptions of the Level 1 model (Mackay \& Seth 2001) which are as follows: the system containing $\mathrm{M}$ moles of the chemical is in thermodynamic equilibrium and the fugacity of the chemical species is the same throughout the system; a multi-compartment "Unit World" is described with the volume of each compartment being $v_{i}$; the chemical does not react and no loss of the chemical is taking place by any means from the unit world, and the system is in steady-state 
with no movement of the chemical from one phase to another. For a multicomponent system, the common fugacity is defined as

$$
f=\frac{M}{\Sigma v_{i} z_{i}}
$$

Where $z_{i}$ is the fugacity capacity of the particular phase for the chemical and is used to relate concentration and $f$ as follows:

$$
c_{i}=f z_{i}
$$

The concentration $c_{i}$ in each compartment can then be calculated from Eqn. 2 and the quantities in each of the compartments

$$
M_{i}=v_{i} f z_{\mathrm{i}}
$$

$z_{i}$ depends upon chemical properties, the nature of the phases, and temperature.

The fugacity capacities of different phases are defined by the flowing equations:

Fugacity capacity of air: $\left(\mathrm{z}_{\mathrm{a}}\right) \quad z_{a}=\frac{1}{R T}$

Fugacity capacity of aerosol: $\left(\mathrm{z}_{\text {aerosol }}\right)$

Where $\mathrm{K}_{\mathrm{qa}}$

$$
z_{\text {aerosol }}=z_{a} \times K_{q a}
$$

$$
K_{q a}=\frac{6 \times 10^{6}}{P_{L}}
$$

$\mathrm{P}_{\mathrm{L}}$ is the subcooled vapor pressure

$$
P_{L}=P \exp \left[6.79\left(T_{\frac{M}{T}}-1\right)\right] \quad \text { at } \quad T<T_{M}
$$

where $T$ is the measurement temperature, $T_{M}$ is the melting point, $\mathrm{P}$ is the vapor pressure at temperature $\mathrm{T}$.

Fugacity capacity of water: $\left(z_{w}\right)$

$$
z=\frac{S}{P}
$$

Where $\mathrm{S}$ is the water solubility $\left(\mathrm{mol} \cdot \mathrm{m}^{-3}\right)$ and $\mathrm{P}$ is vapor pressure $(\mathrm{Pa})$

Fugacity capacity of suspended sediments: $\left(\mathrm{z}_{\text {sus }}\right)$

$$
z_{\text {sus }}=K_{\text {sus }} \times \rho_{\text {sus }} \times z_{w}
$$

Where $K_{\text {sus }}$ is the suspended sediment-water partition coefficient: $\left(\mathrm{K}_{\mathrm{sus}}\right)$

$$
K_{\text {sus }}=K_{o c} \times f o c
$$

and $f_{o c}$ is the fraction of organic carbon present in the suspended particles (taken as constant 0.02 in EQC standard environment).

Fugacity capacity of fish: $\left(\mathrm{Z}_{\text {fish }}\right)$

$$
Z_{f i s h}=K_{f i s h} \times \rho_{f i s h} \times Z_{w}
$$

Where $K_{\text {Fish }}$ is the Fish-Water Partition Coefficient or Bioconcentration Factor:

$$
K_{\text {Fish }}=10^{\log k_{\text {ow }}} \times L
$$

Where $\mathrm{L}$ is the fraction of lipid content in fish (taken as constant 0.05 in EQC standard environment).

and $\mathrm{K}_{\mathrm{Fish}}$ is the density of fish present (taken as constant 1.0 $\mathrm{kg} . \mathrm{L}^{-1}$ in EQC standard environment).

Fugacity capacity of soil: $\left(\mathrm{Z}_{\text {soil }}\right)$

$$
Z_{\text {soil }}=K_{\text {soil }} \times \rho_{\text {soil }} \times Z_{w}
$$

Where Ksoil is the Soil-Water Partition Coefficient:

$$
K_{\text {soil }}=K_{o c} \times f o c
$$

and $\rho_{\text {soil }}$ is the density of soil (taken as constant $2.4 \mathrm{~kg} . \mathrm{L}^{-1}$ in EQC standard environment) and $f_{o c}$ is the fraction of organic compound in soil (taken as constant 0.02 in EQC standard environment) and $K_{o c}$ is the organic carbon-water partition coefficient:

$$
\mathrm{K}_{\mathrm{oc}}=0 \cdot 41 \times \mathrm{K}_{\mathrm{ow}}
$$

Fugacity capacity of sediments: $\left(\mathrm{Z}_{\text {sed }}\right)$

$$
Z_{\text {sed }}=K_{\text {sed }} \times \rho_{\text {sed }} \times Z_{w}
$$

Where $K_{\text {sed }}$ is the sediment-water partition coefficient

$$
K_{\text {sed }}=K_{o c} \times f o c
$$

Where $f_{o c}$ is the fraction of organic compounds in sediments. (taken as constant 0.04 in EQC standard environment). Additionally, Henry's Law constant can be obtained by the equation given as:

$$
H=\frac{P}{S} \times M
$$

Where $\mathrm{P}$ is the vapor pressure and $\mathrm{S}$ is the water solubility and $\mathrm{M}$ is the molecular weight.

\section{Model Inputs}

An examination of the chemical properties of Fluopyram (see below) indicates that it is a Type 1 chemical (Mackay et al. 1996a, Mackay et al. 1996b, Mackay et al. 1996c) with 
vapor pressure $>10^{-7} \mathrm{~Pa}$ and solubility in water $>10^{-6}$ g.m 3 . The EQC Level 1 model requires the following chemical properties as inputs for Type 1 chemicals, the values of which are given for Fluopyram: a) vapor pressure, $1.20 \times 10^{-6} \mathrm{~Pa}$; b) water solubility, $16.0 \mathrm{~g} . \mathrm{m}^{-3}$; c) molar mass, $396.72 \mathrm{~g} \cdot \mathrm{mol}^{-1}$; d) melting point, $117.5 \mathrm{C}$; e) data temperature; $20 \mathrm{C}$ (Pesticide Properties Database, 2019). The EQC model assumes a one-time release and instantaneous equilibration of 100,000 $\mathrm{kg}$ of the chemical which is 256,067 mols of Fluopyram.

The model has an inbuilt 'EQC Standard Environment' which is mentioned in Table 1 . These values are used to calculate the distribution of Fluopyram in the 'Unit World'.

The 'EQC Standard Environment' has been modified to calculate the effect of soil density on the Fluopyram distribution. The following agricultural soil types (Irmak \& Djaman 2015) have been used and their density values are mentioned in parentheses $\left(\mathrm{kg} . \mathrm{L}^{-1}\right)$ a) clay soil (1.15) b) silt loam soil (1.13) c) clay loam soil (1.325) d) loam soil (1.38e) sandy loam soil (1.425) and f) sandy soil (1.45). To calculate the distribution of the effect of sediment density on the Fluopyram distribution, the following sediment types (Flemming \& Delafontaine 2016) have been used and their density values are mentioned in parentheses $\left(\mathrm{kg} . \mathrm{L}^{-1}\right)$, a) muddy sediment $(0.3)$ b) slightly sandy muddy sediment $(0.4)$ c) sandy muddy sediment (0.6) d) muddy sandy sediment (0.9) e) slightly muddy sandy sediment (1.2) and f) sandy sediment (1.5).

Fugacity-based Environmental Equilibrium Partitioning Model Level I (Mackay 2004) have been used to perform the EQC Level 1 calculations for the 'EQC Standard Environment'. The same calculations were performed using MS Excel for convenience and the results matched with the output of the EQC Level 1 program (Table 2). This served as a check on the calculations performed in MS Excel. The density of the soil and sediment compartments were varied systematically and calculations were performed using MS Excel, and the maximum and minimum Fluopyram concentration in different environmental compartments were determined, for different combinations of soil and sediments and are tabulated in Table 3.

\section{RESULTS AND DISCUSSION}

The amounts of Fluopyram (by weight) and its relative distribution in 'Standard EQC environment' in different environmental compartments have been shown in Table 2. There is a large amount (mols) of Fluopyram present in soil (63\%) and water (36\%), followed by sediment compartment (1.4\%) and negligible quantities in the air. Also, the concentration of Fluopyram is more in sediments $>$ soil $>$ water. The air compartment showed very little concentration of the chemical.

The negligible presence of Fluopyram in the air is understandable because of its low vapor pressure. A chemical with a small vapor pressure does not distribute into the air so there is a possibility for accumulation in water if it is water-soluble or soil. However, if it is not water-soluble, the chemical can accumulate in the soil. The water solubility of Fluopyram is moderately low. The predicted large amount of Fluopyram in the soil compartment was noticed. The Henry's Law constant value for Fluopyram is low $H=2.98 ¥ 10^{-5}$ $P_{a} \mathrm{~m}^{3} / \mathrm{mol}$, which indicates that it will distribute to the air compartment. Also, it was noted that in the air compartment Fluopyram concentrations are predicted to be far below the detection limit of $4 \mu \mathrm{g} . \mathrm{m}^{-3}$ (BVL 2017).

The Fluopyram concentrations for all possible combinations of soil and sediment types (details in the Methods section) were calculated and the maximum and minimum values are tabulated for the four main environmental compartments and are depicted in Table 3. The concentrations units used are mol. $\mathrm{m}^{-3}$, for easy comparison amongst compartments with varying density of its constituents.

The highest Fluopyram concentration is predicted to occur in the sediment compartment with clay soil-sandy sediment combination (Fig. 1). An increasing Fluopyram concentration is predicted in sediments with different types of soils, and the order of sediment types can be established as

Table 1: Environmental Parameters Under 'EQC Standard Environment'.

\begin{tabular}{|lllll|}
\hline & Volume, $\mathrm{m}^{3}$ & Density, kg.m ${ }^{-3}$ & Organic carbon, g.g $\mathrm{g}^{-1}$ & Fish-lipid, g.g ${ }^{-1}$ \\
\hline Air & $1.00 \mathrm{E}+14$ & 1.21 & - & - \\
Aerosol & 2000 & 2000 & - & - \\
Water & $2.00 \mathrm{E}+11$ & 1000 & 0.200 & - \\
Suspended particles & $1.00 \mathrm{E}+06$ & 1500 & - & 0.0500 \\
Fish & $2.00 \mathrm{E}+05$ & 1000 & 0.0200 & - \\
Soil & $9.00 \mathrm{E}+09$ & 2400 & 0.0400 & - \\
Sediments & $1.00 \mathrm{E}+08$ & 2400 & & \\
\hline
\end{tabular}




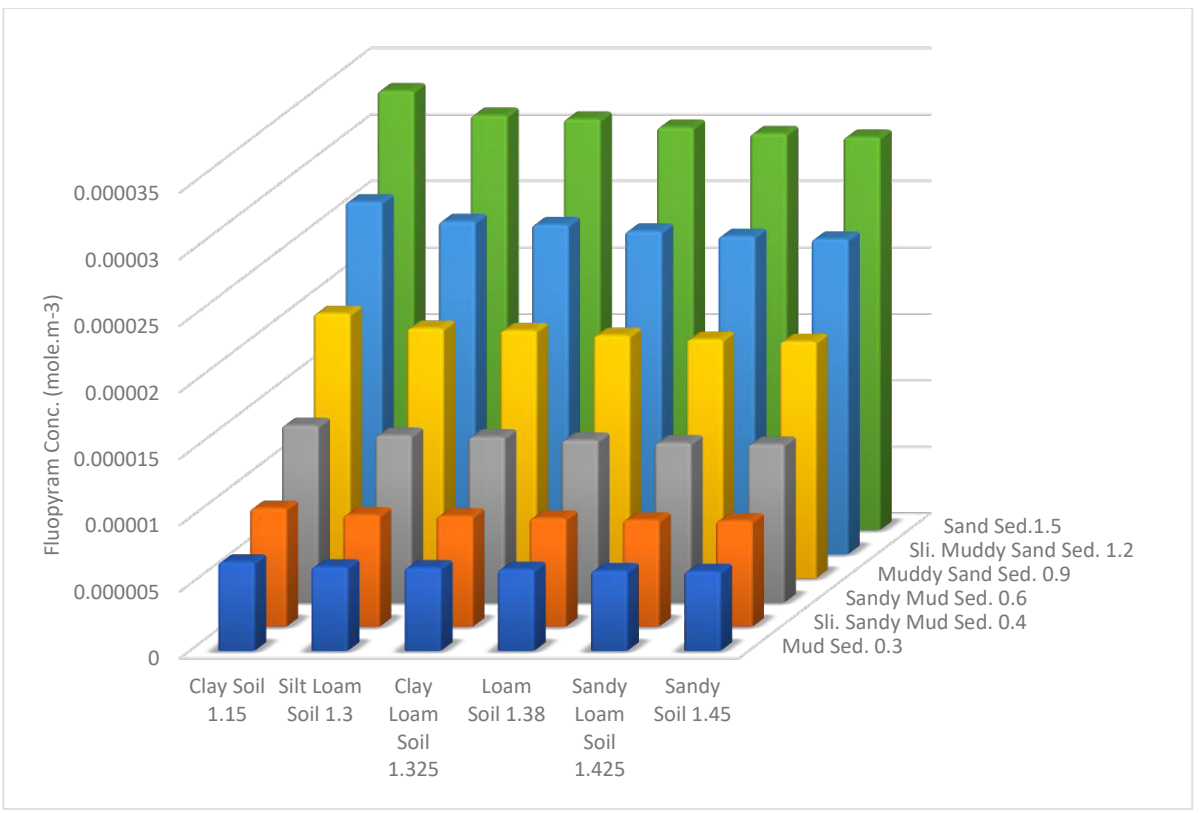

Fig. 1: Graphical representation of variation in concentration of Fluopyram in sediment with different soil and sediment types.

follows: muddy sediment $<$ slightly sandy muddy sediment $<$ sandy muddy sediment $<$ muddy sandy sediment $<$ slightly muddy sandy sediment $<$ sandy sediment. This the same order in which the sediment density increases.

An increasing Fluopyram concentration is predicted in soil with different types of sediment, and the order of soil types can be established as follows: clay soil $<$ silt loam soil < clay loam soil < loam soil < sandy loam soil < sandy soil (Fig. 2). This the same order in which the soil density increases. The Fluopyram concentration is the maximum for sandy soil-muddy sediment combination (Table 3).

Table 3 would be helpful to identify the soil and sediment combination leading to the highest and lowest concentrations of Fluopyram. This would in turn help to understand and guide the use of Fluopyram in different environments with different types of soil and sediment combinations. At the default value of $100,000 \mathrm{~kg}$ application of the Fluopyram, the concentrations of Fluopyram in the soil compartment (Table 2) are above the detection limit $\left(1.5 \times 10^{-3} \mu \mathrm{g} \cdot \mathrm{g}^{-1}\right)$ and lower than the quantification limit $\left(5.0 \times 10^{-3} \mu \mathrm{g} \cdot \mathrm{g}^{-1}\right)$ (FAO

Table 2: Concentration and Amount of Fluopyram in Main Four Different Compartments in EQC Standard Environment at 100,000 kg Emission.

\begin{tabular}{|lllllll}
\hline Compartment & Conc. mol.m ${ }^{-13}$ & Conc. $\mu \mathrm{g} \cdot \mathrm{g}^{-1}$ of solids & Conc. g.m ${ }^{-3}$ & Amount Mol & Amount $\%$ \\
\hline Air & $5.48 \mathrm{E}-15$ & - & $7.17 \mathrm{E}-12$ & 0.548 & $3.17 \mathrm{E}-04$ \\
Water & $4.49 \mathrm{E}-07$ & - & $1.78 \mathrm{E}-04$ & 89778 & 62.9 \\
Soil & $1.76 \mathrm{E}-05$ & $2.19 \mathrm{E}-03$ & $6.99 \mathrm{E}-03$ & $1.59 \mathrm{E}+05$ & 3525 \\
Sediments & $3.35 \mathrm{E}-05$ & $5.83 \mathrm{E}-03$ & $1.40 \mathrm{E}-02$ & 3525 \\
\hline
\end{tabular}

Table 3: Maximum and minimum Fluopyram concentration for different combinations of soil and sediments.

\begin{tabular}{|c|c|c|c|c|c|c|}
\hline \multirow[t]{2}{*}{ Comp. } & \multicolumn{2}{|c|}{$\begin{array}{l}\text { Soil and Sediment combination producing } \\
\text { Max. Fluopyram conc. }\end{array}$} & \multirow[t]{2}{*}{ Conc. $\left(\mathrm{mol} \cdot \mathrm{m}^{-3}\right)$} & \multicolumn{2}{|c|}{$\begin{array}{l}\text { Soil and Sediment combination pro- } \\
\text { ducing Mini. Fluopyram conc. }\end{array}$} & \multirow[t]{2}{*}{ Conc. (mol.m³) } \\
\hline & Soil type & Sed. Type & & Soil type & Sed. Type & \\
\hline Air & Clay soil & Mud sed. & $8.30342 \times 10^{-15}$ & Sandy soil & Sand sed. & $7.35 \times 10^{-15}$ \\
\hline Water & Clay soil & Mud sed. & $6.80161 \times 10^{-7}$ & Sandy soil & Sand sed. & $6.02 \times 10^{-7}$ \\
\hline Sed. & Clay soil & Sand sed. & $3.30346 \times 10^{-5}$ & Sandy soil & Mud sed. & $5.96581 \times 10^{-5}$ \\
\hline Soil & Sandy soil & Mud sed. & $1.44174 \times 10^{-5}$ & Clay soil & Sand sed. & $1.26633 \times 10^{-5}$ \\
\hline
\end{tabular}




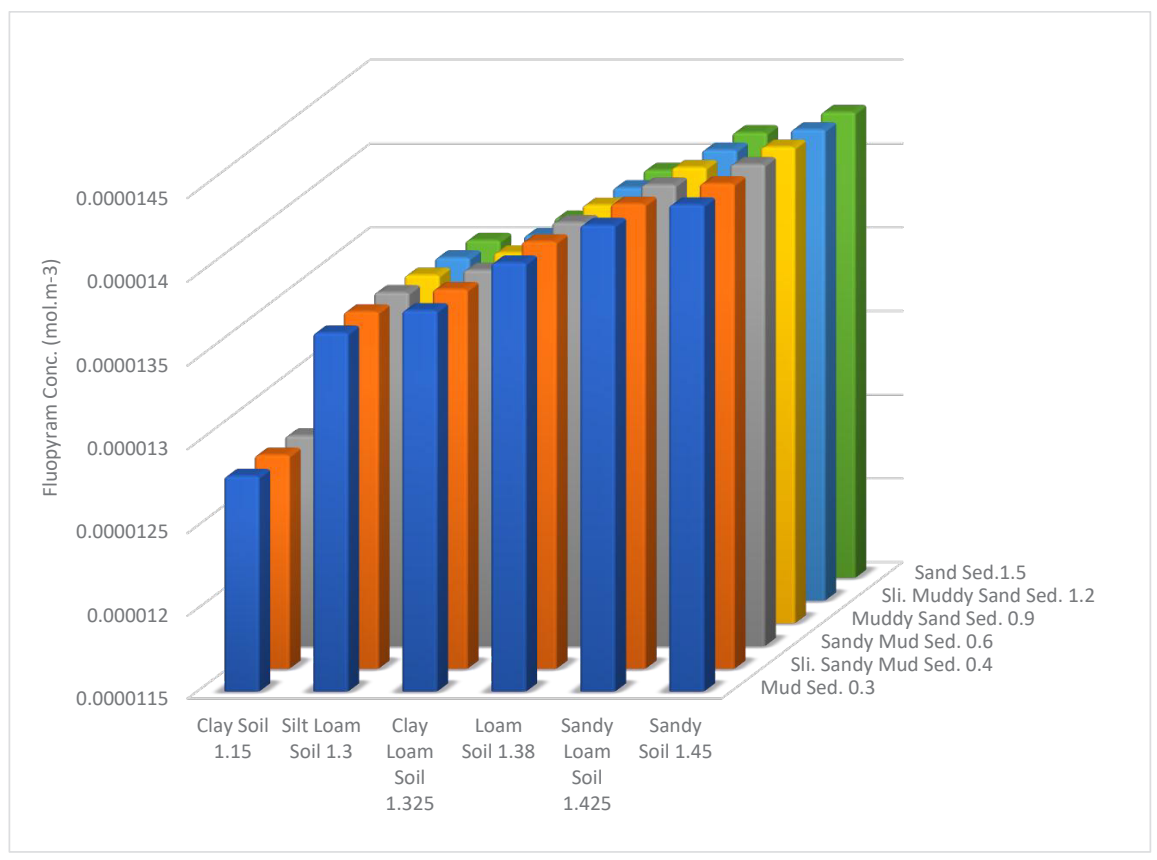

Fig. 2: Graphical depiction of variation in concentration of Fluopyram in soil with different soil and sediment types.

2011). In the case of the sediment compartment, however, the concentration of Fluopyram (Table 2) is above the quantification limit.

\section{CONCLUSION}

To conclude, through this evaluative study, it was understood how the densities of soil and sediment in the environment together with the physico-chemical properties of Fluopyram controls the environmental fate of the pesticide. The EQC Model predicts that Fluopyram mainly distributes (in terms of amount) to soil and water. However, its concentration in the sediment compartment would be maximum. It is also predicted that 'sandy sediment' would be able to concentrate most of the Fluopyram while 'muddy sediment' concentrates the least for all possible combinations of soil and sediment types.

\section{REFERENCES}

Bernardes, M.F.F., Pazin, M., Pereira, L.C. and Dorta, D. J. 2015. Impact of pesticides and human health. In: Andreazza, A. C. and Scola, G. (eds.) Toxicology Studies - Cells, Drugs and Environment, IntechOpen, Rijeka, Croatia, pp. 195-211.

BVL. 2017. Registration Report: National Assessment-Federal Republic of Germany https://www.bvl.bund.de/SharedDocs/Downloads/04_Pflanzenschutzmittel/01_zulassungsberichte/027208-00-00.pdf?_(date accessed 11 October, 2020).

Cahill, T.M., Cousins, I. and Mackay, D. 2003. General fugacity-based model to predict the environmental fate of multiple chemical species. Env. Tox. Chem., 22(3): 483-493.
Di Guardo, A., Gouin, MacLeod, M.T. and Scheringer, M. 2018. Environmental fate and exposure models: Advances and challenges in 21st century chemical risk assessment. Env. Sci. Process. Imp., 20(1): 58-71.

Duran-Lara, E.F., Valderrama, A. and Marican, A. 2020. A natural organic compound for application in organic farming. Agriculture, 10(2): 41-63.

EFSA. 2013. Conclusion on the peer review of the pesticide risk assessment of the active substance [fluopyram]. EFSA J., 11(4): 3052-3128.

Ellis, D.A., Cahill, T.M., Mabury, S.A., Cousins, I.T. and Mackay, D. 2006. Partitioning of Organofluorine Compounds in the Environment. In: Neilson A.H. (eds) Organofluorines, The Handbook of Environmental Chemistry (Vol. 3 Series: Anthropogenic Compounds), vol 3N. Springer, Berlin, Heidelberg, pp. 63-83.

FAO. 2011. Fluopyram. http://www.fao.org/fileadmin/templates/agphome/ documents/Pests_Pesticides/JMPR/Evaluation10/Fluopyram.pdf_date accessed 11th October, 2020).

Flemming, B.W. and Delafontaine, M.T. 2016. Mass physical sediment properties. In: Michael J. (eds.). Encyclopedia of Estuaries, Springer, Netherlands.

Irmak S. and Djaman, K. 2015. Basic Soil and Water Resources and Irrigation Engineering/Agricultural Water Management and Related Terminology. https://extensionpublications.unl.edu/assets/pdf/ec2009. pdf (date accessed 6 Nov. 2020)

Kim, J., Powell, D.E., Hughes, L. and Mackay, D. 2013. Uncertainty analysis using a fugacity-based multimedia mass-balance model: Application of the updated EQC model to decamethylcyclopentasiloxane (D5). Chemosphere, 93(5): 819-829.

Lifongo, L. and Nfon, E. 2009. Evaluating the fate of organic compounds in the Cameroon environment using a level III multimedia fugacity model. Afri. J. Env. Sci. Tech., 3(11): 376-386.

Mackay, D. 2004. Fugacity-Based Environmental Equilibrium Partitioning Model Level I Model, Version 3.00. Trent University, Peterborough, Canada.

Mackay, D. 2001. Multimedia Environmental Models. The Fugacity Approach. 2nd ed. Lewis Publication, Boca Raton, FL, USA. 
Mackay, D., Paterson, S., Kicsi, G., Di Guardo, A. and Cowan, C.E. 1996a. Assessing the fate of new and existing chemicals: A five-stage process. Environ. Toxicol. Chem., 15(9): 1618-1626.

Mackay, D., Paterson, S., Di Guardo, A. and Cowan, C.E. 1996 b. Evaluating the environmental fate of a variety of types of chemicals using the EQC model. Environ. Toxicol. Chem., 15(9): 1627-1637.

Mackay, D., Paterson, S., Kicsi, G., Cowan, C.E., Di Guardo, A. and Kane, D.M. 1996c. Assessment of chemical fate in the environment using evaluative, regional, and local-scale models: Illustrative application to chlorobenzene and linear alkylbenzene sulfonates. Environ. Toxicol. Chem., 15(9): 1638-1648.

Mackay, D. and Seth, R. 2001. Fugacity Modelling to Predict Long-Term Environmental Fate of Chemicals from Hazardous Spills. In: Fingas. E., (eds.) The Handbook of Hazardous Materials Spills Technology, McGraw-Hill, New York, N.Y., pp. 483-493
Macleod, M. and Mackay, D. 1999. An assessment of the environmental fate and exposure of benzene and the chlorobenzenes in Canada. Chemosphere, 38(8): 1777-1796.

Malhotra, S.K. 2018. Minutes of the $384^{\text {th }}$ Meeting of Central Insecticides Board \& Registration Committee, Ministry of Agriculture \& Farmers Welfare, GoI, http://164.100.161.213/sites/default/files/384rc2018.pdf (date accessed 11 October, 2020).

Ndouba, A.M., Elleingand, E.F. and Wandan, E.N. 2020. Modelling the fate of pesticides applied to banana plantation in the Bia river watershed in Côte d'Ivoire. J. Chem. Biol. Phys. Sci., 10(3): 251-264.

Persistence Market Research 2020. Fluopyram Market. https://www.persistencemarketresearch.com/market-research/fluopyram-market.asp_date accessed 11 October, 2020).

Pesticide Properties Database. 2019. PPDB: Pesticide Properties Database. http://sitem.herts.ac.uk/aeru/ppdb/en/Reports/1362.htm (date accessed 11 October, 2020). 